\title{
Your second home- Your orthodontic office!!
}

\author{
Toushith Kaur ${ }^{1, *}$, Naveen $\mathbf{R}^{2}$, C. Sunitha ${ }^{3}$, P. Kiran Kumar ${ }^{4}$, T. Saritha ${ }^{5}$ \\ ${ }^{1}$ PG Student, ${ }^{2}$ Reader, ${ }^{3}$ Professor and Head, ${ }^{4}$ Reader, ${ }^{5}$ Reader, Dept. of Orthodontics \& Dentofacial Orthopedics, Mamata Dental \\ College, Telangana, India
}

*Corresponding Author: Toushith Kaur

Email: toushith_k@yahoo.co.in

\begin{abstract}
Most orthodontists spend the entire day working in their offices. Therefore, it is important that the office be planned to make those hours as efficient and satisfactory as possible. The office should not only be a congenial space for the orthodontist to be in, but also a comfortable place for the staff and patients as well. In this competitive world where time and attention are of utmost importance, appropriate office design will help the orthodontist to stand out and achieve his goals, which in turn will help improve the practice.
\end{abstract}

Keywords: Orthodontic office, Design, Planning.

\section{Introduction}

An efficiently designed office creates a lasting impression on the patients, making them more interested in starting treatment with the orthodontist. With a suitable design, the orthodontist can express his mission and make his message heard.

The office should be functionally appropriate to allow for maximum efficiency in both clinical and administrative tasks. The design should be planned according to function and not by adapting function to a prearranged design. ${ }^{1}$

Before implementing the design of the clinic, the doctor should be well versed with the legal and statutory requirements of various government agencies. ${ }^{2}$

Ergonomics will determine the size, equipment and feeling of the office. ${ }^{3}$ Accessibility for differently-abled patients should also be considered while planning the office. ${ }^{4}$ Burglary and fire alarms are a must.

Site planning and Topographic Map: Apart from considering the demographics of the area like proximity to schools, colleges etc, it is also important to conduct site planning before buying property for an orthodontic office. Site planning is the art and science of maximizing and arranging the use of land which requires the expertise of architects, planners, and engineers for the development of extensive tracts of land.

After deciding on potential locations, two major reports should be created for each site: a legal code analysis and a land analysis. ${ }^{2}$ Legal code analysis involves evaluation of building's zoning category, compatibility of surrounding areas, future road widening, sidewalk placement and width etc whereas land analysis involves evaluation of soil testing, topographic survey, drainage analysis, environment audit, vegetation analysis etc.

A Contour or Topographic map is also important for the planner. Contour lines help to visualize the land in three dimensions by showing elevations of the topography. ${ }^{2}$ The main purpose of a contour map is to help the designer in developing a plan for grading and earthwork. If the land is not completely flat, the contour may need to be changed by the landscaper to adapt the costruction to the existing topography, which can give the area a unique esthetic appearance.

Parking: Land should be purchased after the buyer has determined its setbacks, rights of way and other legal and statutory requirements that may shrink the space available for the site. ${ }^{2}$ Inadequate parking space is one reason that made some orthodontists to leave central and developed areas and settle for the suburbs. The parking area will be decided by the local zoning board, whose approval is necessary to gain permit for construction.

Working with an Architect and Interior Decorator: Selecting an architect or interior decorator mainly depends on the fee that one is able to pay them. ${ }^{5,6}$ There are two modes of payment of their fees- One is a fixed percentage of the cost of construction and the other is a fixed fee for the total project. This prevents any lavish or exaggerated expenditure that might increase the cost of the project substantially.

Principles of Office Design: While designing an office, the orthodontist usually has large ideas but insufficient space. ${ }^{7}$ This situation can be avoided by drawing a preliminary floor plan. The plan should be exact in dimensions and should fulfill the requirements of the practice ${ }^{8}$ An efficient method to start the project is to set an aim and differentiate between the essential and nonessential components in the office. ${ }^{1}$

Essential Components include: Reception/Waiting area, treatment/operating room, sterilization area, consulting desk.

Non Essential Components are: Consulting room, multiple treatment rooms, laboratory, restroom, X-ray and photography room, store.

Reception/Waiting Room: The entrance and the reception area of the office should highlight the principles of the orthodontist. It is an area that should assure the patient that they have come to the right place. The architecture and interiors of it should calm the patients' anxiety. A minimum area of 60 square feet is required to accommodate 6 to 9 people. ${ }^{1}$ 
In a well-designed office, the reception room is often one of the best-decorated rooms. The reception desk position is also important in determining the patient traffic flow pattern of the office. ${ }^{9}$ There are excellent floor plans with either straight-line or circular traffic flow. Individual seating is mostly preferred over continuous style seating.

Many dentists are now offering amenities like coffee corner, outlets for laptops, wifi and gaming equipment for children and entertainment systems to relax and occupy the patient before the appointment. ${ }^{1}$

Attention should also be given to literature placed in the waiting area, which should not be related to just orthodontics but various others like current trends, car magazines, story books etc.

Consultation Room: It is usually advisable to have a separate sound-insulated cubicle close to the reception area for discussion of financial arrangements as well as for conflict resolution. At least 80 square feet should be kept for the business purpose. ${ }^{1}$ This room can also be used as a patient education and audiovisual centre.

Treatment Room: Treatment area concepts can be of three types ${ }^{1}$ -

1. Open bay

2. Semi-private

3. Individual treatment rooms

Open-bay treatment rooms are recommended in offices with limited space to make place for as many dental chairs as possible but this concept does not provide privacy to the patients during treatment. ${ }^{10}$

This kind can be adopted in busy individual practices where youngsters are seen for short appointments, as well as in institutions and general hospitals. Usually, dental chairs are placed about $1.8 \mathrm{~m}$ (6 feet) apart (as measured from the centre of the chair). ${ }^{1}$

Semi-private treatment rooms are preferred when the doctor prefers to see more than one patient at a time while maintaining some privacy for the patient. Visual barrier is provided by a partition between the dental chairs. Due to incomplete partitioning, the sounds of treatment and conversation cannot be restricted. Glass is most widely used material for such partitions because of its esthetic appearance, affordable price and ease of maintenance. But, it is not sound-absorbing, like some of the other materials such as gypsum board etc.

Individual treatment rooms are closed cubicles, with only one dental chair in each room. They are suitable for the privacy of the patient and general clinic environment as they inhibit transmission of treatment sounds such as the whine of the dental turbine, ultrasonic scaler etc.

Entry and exit options for these treatment rooms should also be considered. The patient's entry into the treatment room should not be from the foot end of the dental chair. ${ }^{11}$

It is also important that at least one treatment room be large enough to position a wheelchair next to the dental chair. An important aspect in dental office design is to have a minimum space of $76 \mathrm{~cm}$ (30 inches) all around the chair for hassle free traffic flow. ${ }^{1}$

The support equipment should also be within easy reach of the dentist or the assistant. Storage racks and cabinets must be functionally convenient to access. The standard height of the counter top is $90 \mathrm{~cm}$ (36 inches). ${ }^{1}$ An inert material should be preffered as the counter top and usually glass is used. Cabinetry can be positioned off the wall or floor mounted. Off the wall cabinets do not accumulate dust as much whereas floor mounted cabinets should have tight seal to avoid the same.

Two to four or more chairs in one large area, often in a row or a circular pattern, adjacent to central supply cabinets, constitute the current trend in the furnishing of the modern orthodontic treatment room. The dominant feature of this design is a double-tiered rotating "Lazy susan" cabinet located in the centre of the room, with each dental unit and chair at a diagonal relation to this cabinet. ${ }^{11-13}$

Position of compressor and suction units should be pre planned while designing the clinic layout. They should be located in a separate mechanical room away from the treatment zone so that their sound is contained within. The compressor and suction pipes should be under the floor. ${ }^{10}$

Sterilization Room: It is preferable to purchase the sterilization equipment such as autoclaves and ultrasonic cleaners early so that they can be accomodated into the design. The sterilization area should have a soiled side and a clean side with a sequential progression to the other.

Placement of scrub sink, ultrasonic cleaners and sterilization equipment should be ordered indicating that the items for sterilization should pass through these levels and end up in a storage area for sterilized items. A minimum space of 60 square feet with 12 feet to 16 feet of counter space for sterilization procedures is considered ideal. ${ }^{1}$

The orthodontist will need to decide in advance how extensive the in-office laboratory and cephalometric area needs will be and provide a separate space for these. ${ }^{8}$

Impression Tray Holder: Prevents leaning distortion of alginate impressions and stone models, neat appearance, inexpensive, easy to construct, maintenance free. ${ }^{14}$

Model Storage: Unlike typical storage methods, which rely on box labeling for model identification and retrieval, the coordinate system uses box position. Every set of models has a four-digit number that identifies its location. Numbers on certain boxes are not labels, but grid coordinates like latitude and longitude on a map. ${ }^{10,15}$ Emergencies during the Practice: An Orthodontist may also face an untoward medical emergency during the course of practice for which he/she should be prepared and well equipped and thorough with the methods of offering first aid care to such patients. Contact details of emergency care services should also be kept at hand. Certain emergency care kit offering 
artificial oxygen or drugs should be kept ready at all times and checked regularly for expiry dates etc.

Acoustics Planning and Sound Control: Efficiency suffers and irritability and stress set in on everyone to some degree when they are exposed to a prolonged atmosphere of noise. In addition to a psychological fatigue factor, this becomes an economic factor when the efficiency of the doctor and staff are affected. ${ }^{16}$

Sound control problems are broadly classified according to whether they involve sound originating within a room or space, or from the outside. ${ }^{16,17}$ In many cases, both problems are involved. The primary solution to problems originating within a space is by applying sound absorbing materials to the interior surfaces, to reduce reverberation. The solution to problems involving sound originating outside a room or space involves sound insulation or sound isolation.

Creating a Feeling of Space: One of the most common complaints from those who are planning a new office is that their present office seems cramped because of increased rent and maintenance costs. Some practical solutions for this are-

1. Open Bay Operatory: This was the answer to the confining $8^{\prime}$ x $10^{\prime}$ cubicles, typically lined up down a narrow hallway. ${ }^{18}$ Traffic pattern going through the middle of a small room should be avoided.

2. Vaulted and Beamed Ceilings: When we increase the height of the traditional eight or nine foot suspended ceiling, the cost rises, but it is obvious that this type of ceiling treatment creates a very special feeling. ${ }^{18}$

3. Floating Ceiling: It is the ceiling treatment with an additional design of the lighting against the walls that makes the ceiling appear to float within the room. The illusion of a floating ceiling is not limited to large rooms. Its expansive characteristics is more appreciable in smaller and cramped areas. ${ }^{19}$

4. Mirrors: The use of a mirrored wall, or section of a wall, can create a startling effect with a feeling of space, and expand one's comfort zone at the same time. This is especially true when an entire wall in a small cramped room receives a mirror. ${ }^{18,20}$

5. Windows: Large, floor-to-ceiling windows of the entire length of the operatory can give patients a feeling of being in a garden while they are having their treatment. ${ }^{18}$ This helps create the effect of doubling the operatory size, and provides a less stressful environment for the doctor and staff.

6. Borrowed Light: It describes the use of windows between rooms to transmit light between rooms or from one space to another. ${ }^{19}$

7. Wall Murals: Murals with 3D designs can lead the eye back 30' or more, and can give a feeling of space much like a mirror. ${ }^{19}$

8. Furniture and Blinds: Avoid bulky overstuffed sofas in small areas. Consider armless sofas and chairs. Avoid bulky coffee tables or chairside tables. ${ }^{19}$ Treat windows as simply as possible.
Heavy drapes are out. Metal or textured blinds, with a variety of colours and patterns can bring warmth to a room.

9. Colour: Colour can be introduced into an interior in many different ways, from books on a shelf to a garden of fresh flowers to the more obvious techniques of painting and papering the walls. Colour harmony depends not only on combinations of hues, but on the quantity of colours and the balance of their intensity. Warm colours (reds) tend to call people to action; cool colours (blues and greens) promote a feeling of well being. ${ }^{21}$ People tend to overestimate the passage of time in a red room and underestimate it in a green room. Violet, which combines red and blue, is the most relaxing colour. Black can be depressing.

10. Floor Treatment: Avoid dark colours and busy, large-block designs in small areas. ${ }^{19}$

\section{Remodelling}

The term "remodelling", as applied to an orthodontic office, can cover a wide range of activities from minor alterations in an existing floor plan for improved practice efficiency to major, all-encompassing projects requiring both internal and external changes. To help avoid cost overruns, specific project goals should be established; in most cases, especially if structural changes are involved, professional help will be required. 22,23

\section{Digitization}

Computer usage for the benefit of patients, staff, and clinician in an orthodontic office has assembled an impressive array of computer tools for a multitude of practical office applications. ${ }^{24-26}$ Location of the required number of computers, scanners and networking equipment along with the necessary electrical outlets and hard-wired and wireless connections be pre planned. The computer system should be designed taking into account security of the data and the possibility of a malicious incursion.

At Patient Interface: For appointment scheduling, reminder e-mails, e-mailing photographs and $\mathrm{x}$-rays.

Doctor Uses: For remote access to patient charts, consulting other dentists on multidisciplinary cases, internet study club, filing taxes etc

Office Staff Uses: For inventory control, credit checks, lab consultation etc.

\section{The Future}

Currently on the horizon are the increasing applications and accessibility of 3D printing with medical-grade, biocompatible materials. ${ }^{27}$ Software developers have already begun to deliver tools for the creation of oral appliances directly from the virtual patient, with the ability to output in the standard STL and OBJ file formats accepted by most 3D printers. The ability to create highly accurate, customizable appliances 
for each patient enables the orthodontist to deliver more effective treatment.

\section{Conclusion}

In this way, a sample layout for an orthodontic office successfully designed with the above principles must be integrated with specific plumbing, electrical and building limitations. Finally, before designing an orthodontic office do make it a point to visit nearby orthodontic offices for better understanding and then try and adopt, adapt and innovate keeping these factors in mind and build your dream practice. Thus, it is imperative to know the design goals before details can be implemented in an effective office layout.

\section{References}

1. Varghese J, Doshi V. Orthodontic office design: Principles and practice. Semin orthod. 2016;23:1-19.

2. Hamula W, Hamula D.W, Dwyer F. Orthodontic office design- Site planning. J Clin Orthod. 1997;31:47-61.

3. Berstein L. Designing an efficient and economical operatory. J Clin Orthod. 1969;3:645-52.

4. Hamula W, Hamula D.W. Orthodontic office design- The Americans with disabilities act. J Clin Orthod. 1993;27:691-705.

5. Hamula W, Dwyer F. Orthodontic office designWorking with an architect. J Clin Orthod. 1990;24:95107.

6. Hamula W, Gay C.C. Orthodontic office designWorking with an interior decorator. J Clin Orthod. 1991;25:35-43.

7. Peck S, Peck H. "Principles of orthodontic office design. Angle Orthod. 1974;44:162-66.

8. Hamula W. Orthodontic office design- Developing a floor plan. J Clin Orthod. 1984;18:719-25.

9. Hamula W. Orthodontic office design. Reception deskplacement and design. J Clin Orthod. 1985;19:722-28.

10. Jacobson S. Orthodontic office planning. J Clin Orthod. 1974;8:103-113.

11. Ouellette P.L. Planning and designing the orthodontic office. J Clin Orthod. 1982;16:821-32.

12. Douglas J.P. An optimal design for the compact multi unit orthodontic operatory. J Clin Orthod. 1974;8:570-75.

13. Paskow H. Orthodontic treatment in the round. J Clin Orthod. 1970;4:578- 83.

14. Greene A.G. "Clinical aids- Impression tray holder. $J$ Clin Orthod. 1968;2:419- 20.

15. Howe R.P. “A coordinate system for model storage. $J$ Clin Orthod. 1985;19:640- 51.

16. Hamula W. Orthodontic office design- Practical acoustical planning and sound control. J Clin Orthod.1981;15:485-96.

17. Hamula W. Orthodontic office design- Sound transmission and wall construction. J Clin Orthod. 1988;22:32-33.

18. Hamula W. Orthodontic office design- Creating a feeling of space Part 1. J Clin Orthod. 1984;18:29-38.

19. Hamula W. "Orthodontic office design-Creating a feeling of space Part 2." J Clin Orthod 1984;18:117-27.

20. Hamula W. "Orthodontic office design- Applications of glass block." J Clin Orthod 1993;27:249-56.

21. Hamula W, Brouwer K. Orthodontic office designColor: the first impression. J Clin Orthod. 1987;21:97101.
22. Hamula W. Remodeling options and solutions. J Clin Orthod. 2011;45:41-47.

23. Hamula W. "Orthodontic office design- Remodeling exterior additions. J Clin Orthod. 1992;26:101-110.

24. Hamula W, Schnaitter D. Computer technology and HIPAA. J Clin Orthod. 2003;37:533-40.

25. Mah J, Haeger R.S. The cutting edge- How I use internet in my office. J Clin Orthod. 2002;36:447-50.

26. Haeger R.S. The cutting edge- Establishing an all digital office. J Clin Orthod. 2005;39:81-95.

27. Ahmed F.S, Kanna A.A, Kumar V.R. The cutting edge: 3D printed orthodontic auxillaries. J Clin Orthod. 2015;49:337-41. 